\title{
Unusual Traumatic Injury Causing Hard Palate Perforation
}

\section{Santosh Patil ${ }^{1}$ and Suneet Khandelwal ${ }^{\star 2}$}

${ }^{1}$ Department of Oral Medicine and Radiology, Jodhpur Dental College, Jodhpur (Rajasthan), India

${ }^{2}$ Department of Oral Pathology and Microbiology, Desh Bhagat Dental College, Muktsar (Punjab), India

\begin{abstract}
Traumatic lesions in the oral cavity occur frequently in clinical practice. Most of the acute or chronic injuries of soft tissues were aroused from incorrect hygienic procedures or iatrogenic injuries. Origin of these conditions, location and clinical signs may be considerably different. They can appear typically and sometimes present bizarre characteristics. Palatal perforation is a rare condition encountered in the routine dental practice. Hard palate perforation may be seen due to various etiologic factors such as developmental, infections, malignancy. Trauma is known to be one of the rarest causes leading to palatal perforation. This case is being reported for its rarity. Here an unusual case of a 28-year-old male patient with perforation in the midline of hard palate secondary to accidental injury from a horn of a calf. The patient was operated surgically for closure of the hard palate perforation and there were no complications noted on follow up.
\end{abstract}

Keywords: Developmental; Palate; Perforation; Trauma; Tumors

\section{Introduction}

Palatal perforation can be defined as a communication between the nasal cavities and the oral cavity. There are various potential causes of palatal perforation. Failure of the palatal shelves to close during the sixth week of prenatal period results in cleft palate. Maternal alcohol consumption and cigarette smoking, folic acid deficiency, teratogenic drugs, certain viruses, corticosteroid use and anticonvulsant therapy are some of the environmental factors known to cause cleft palate [1]. Various infectious and granulomatous diseases, such as leprosy, tertiary syphilis, tuberculosis, rhinoscleroderma, naso-oral blastomycosis, leishmaniasis, actinomycosis, histoplasmosis, coccidiomycosis and diphtheria are reported to perforate the palate. Palatal perforation is also seen in autoimmune diseases like lupus erythematous, sarcoidosis, Crohn's disease and Wegener granulomatosis [2].

Minor salivary gland malignancy adenoid cystic carcinoma is reported to cause palatal perforation [3]. Tumors can extend from maxillary sinus or nasal cavity and perforate the palate [4]. Although these neoplasms usually form a mass, but in advance cases perforation of palate may occur in course of disease or following treatment. Palatal perforation due to cocaine abuse is a well-known situation. Other drugs (heroine, narcotics) can be responsible for palatal perforation [5].

Sometimes following a surgical procedure such as tumor surgery, corrective surgeries or intubation can cause palatal perforation. Rare cases in which rhinoliths lead to palatal perforation have also been reported in literature [6]. The aim of presenting this case is to emphasize that, such rare type of traumatic injury could be an etiological factor causing perforation of hard palate.

\section{Case Report}

A 28-year-old male farmer reported to clinics with hole in the hard palate since 3 months. Patient had difficulty while eating and hoarseness of voice and change in speech. The patient revealed that, the perforation was resulted secondary to the injury led by a horn of a calf while working in his fields. The patient initially visited the primary health care centre nearby and was referred to us from the authorities there. There was no significant medical history and personal history. Examination confirmed nasal speech, intra-orally; an oval shaped perforation of the hard palate was noted in the midline. It was measuring about $2 \mathrm{~cm} \mathrm{x}$ $1 \mathrm{~cm}$, extending anteriorly up to rughae area and posteriorly till the first molars (Figure 1). No any signs of inflammation noted. Maxillary occlusal radiograph revealed a well defined radiolucency in the anterior region of the hard palate. Patient was managed successfully with conventional surgical approach (palatoplasty) with no post-operative complications (Figure 2).

\section{Discussion}

The palate is a complex part of the oral cavity with a variety of tissue types that give rise to a variety of pathologies. Understanding these conditions requires appreciation of the different tissues native to the palate and their complexity. Palatal perforation may be due to congenital or acquired causes. Acquired palatal perforations may be idiopathic or can be due to trauma, infectious processes, granulomatous disease, drug abuse, collagen vascular diseases, radiation arteritis, primary and secondary malignancies. Case reported here is first of its kind, where animal injury leading to perforation of the hard palate. Cases of traumatic palatal perforations have been reported in the literature but not secondary to the animal injuries. Hwang and Kim reported a case of submucous cleft palate in a 27 -year-old woman

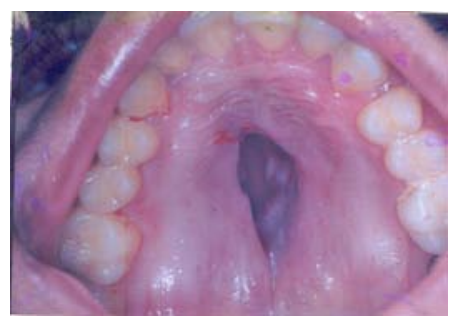

Figure 1: Perforation of the hard palate.

*Corresponding author: Suneet Khandelwal, Department of Oral Pathology and Microbiology, Desh Bhagat Dental College, Muktsar (Punjab), India, Tel: +91 97850 10007; E-mail: khandelwalsuneet@yahoo.co.in

Received March 28, 2012; Accepted April 20, 2012; Published April 23, 2012

Citation: Patil S, Khandelwal S (2012) Unusual Traumatic Injury Causing Hard Palate Perforation. J Trauma Treat 1:133. doi:10.4172/2167-1222.1000133

Copyright: (c) 2012 Patil S, et al. This is an open-access article distributed under the terms of the Creative Commons Attribution License, which permits unrestricted use, distribution, and reproduction in any medium, provided the original author and source are credited. 
Citation: Patil S, Khandelwal S (2012) Unusual Traumatic Injury Causing Hard Palate Perforation. J Trauma Treat 1:133. doi:10.4172/21671222.1000133

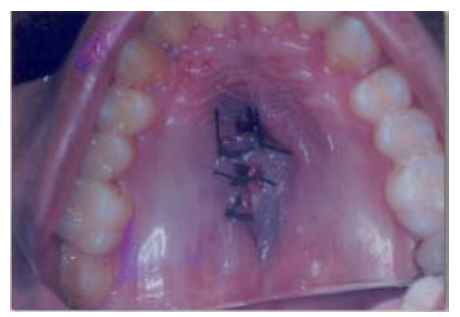

Figure 2: Closure of the palatal perforation.

because of ingestion of hot food (Thermal injury). Perforation and midline notching at the posterior edge of the hard palate was seen noted [7]. A case of 69 years male patient was reported by Macleod in which perforation of the hard palate secondary to pressure atrophy was noted [8]. Ozul et al. [9] reported a case in which perforation of hard and soft palate is seen after a long intubation period. A case of palatal perforation in a 36-year-old female patient treated for empyema of maxillary sinus was reported by Pegler [10]. Differential diagnosis of a lesion presenting as palatal perforation should include infections (syphilis, leprosy, tuberculosis, diphtheria, mucormycosis, actinomycosis) tantrum oris, mechanical trauma, intranasal cocaine abuse, malignancies (especially nasal $\mathrm{T}$ cell lymphomas, carcinoma, melanoma), collagen vascular diseases (Wegener's granulumatosis, systemic lupus erythematosus), sarcoidosis and idiopathic cause such as midline non-healing granuloma [11].

\section{Conclusion}

Traumatic injuries to maxillofacial region are quite common but this report presents a unique type of traumatic injury causing perforation of palate.

\section{References}

1. Amaratunga NA (1989) A study of etiologic factors for cleft lip and palate in Sr Lanka. J Oral Maxillofac Surg 47: 7-10.

2. Karabulut AB, Kabakas F, Berköz O, Karakas Z, Kesim SN (2005) Hard palate perforation due to invasive aspergillosis in a patient with acute lymphoblastic leukemia. Int J Pediatr Otorhinolaryngol 69: 1395-1398.

3. Ferrazzo KL, Schneider PP, Shinohara EH (2011) An unusual case of adenoid cystic carcinoma with hard palate perforation. Minerva Stomatol 60: 83-86.

4. Chaudhary SV, Karnik ND, Sabnis GR, Patil MV, Bradoo RA (2011) Extranodal NK/T cell lymphoma presenting as palatal perforation with oronasal fistula. $J$ Assoc Physicians India 59: 112-114.

5. Silvestre FJ, Perez-Herbera A, Puente-Sandoval A, Bagán JV (2010) Hard palate perforation in cocaine abusers: a systematic review. Clin Oral Investig 14: 621-628.

6. Pinto LS, Campagnoli EB, de Souza Azevedo R, Lopes MA, Jorge J (2007) Rhinoliths causing palatal perforation: case report and literature review. Ora Surg Oral Med Oral Pathol Oral Radiol Endod 104: e42-e46.

7. Hwang K, Kim YS (2010) Perforation in submucous cleft palate due to thermal injury. J Craniofac Surg 21: 280-281.

8. Macleod AL (1927) Perforation of hard palate. Proc R Soc Med 20: 1096.

9. Ozgul S, Tezel E, Numanoglu A (2005) Palatal perforation after long intubation period. Eur J Plast Surg 27: 335-337.

10. Pegler LH (1910) Traumatic (post-operative) Perforation through the Hard Palate, communicating with the Floor of Left Nasal Fossa and Maxillary Antrum. Proc R Soc Med 3: 146.

11. Bains MK, Hosseini-Ardehali M (2005) Palatal perforations: past and present Two case reports and a literature review. Br Dent J 199: 267-269. 